\title{
La Asamblea del año XIII. Artigas y el surgimiento del federalismo en el Río de La Plata
}

The Assembly of the year XIII. Artigas and the emergence of federalism in the Río de La Plata

A Assembléia do ano XIII. Artigas e o surgimento do federalismo no Rio de La Plata

L'assemblée de l'an XIII. Artigas et l'émergence du fédéralisme dans le Rio de La Plata

\begin{tabular}{l|l} 
Guillermo Raúl Moreno $^{1}$ & $\begin{array}{l}\text { Universidad Nacional } \\
\text { de La Plata }\end{array}$
\end{tabular}

Revista Derechos en Acción

Año 3/NNo 9 Primavera 2018, 121-147

DOI: https://doi.org/10.24215/25251678e216

ORCID: https://orcid.org/0000-0002-6334-659X

Recibido: 10/08/2018

Aprobado: 01/11/2018

Resumen: En el presente trabajo se analiza la labor y las circunstancias históricas que rodearon al primer Congreso argentino: La Asamblea Constituyente del Año XIII. Sus objetivos fueron la declaración de independencia y el dictado de una Constitución. Por dificultades internas, falta de una genuina representación popular, sumado a los acontecimientos que se dieron al mismo tiempo en Europa, como la abdicación de Napoleón y la vuelta al trono de España de Fernando VII, la Asamblea no logró ninguno de sus dos objetivos. No obstante ello, la Asamblea General Constituyente de 1813 tomó decisiones soberanas que claramente allanaron el camino a la independencia nacional. En cuanto a su labor constituyente, si bien no sancionó una Carta Magna,

\footnotetext{
1 Guillermo Raúl Moreno, Abogado, Prof. Adjunto de Historia Constitucional, Facultad de Ciencias Jurídicas y Sociales de la Universidad Nacional de La Plata.

Contacto: guillermoraúlmoreno@yahoo.com.ar
} 
si fueron presentados proyectos constitucionales con un innegable valor como antecedentes en la materia. Asimismo, nos detenemos en el análisis de la figura y el pensamiento de José Gervasio Artigas, precursor indiscutido del federalismo en el Río de la Plata.

Palabras Claves: Historia Constitucional; Asamblea Constituyente del Año XIII; Federalismo; Artigas.

Abstract: This paper analyzes the work and the historical circumstances surrounding the first Argentine Congress: The Constituent Assembly of the XIII Year. Its objectives were the declaration of independence and the dictation of a Constitution. Due to internal difficulties, lack of genuine popular representation, added to events that occurred at the same time in Europe, such as the abdication of Napoleon and the return to the throne of Spain of Ferdinand VII, the Assembly did not achieve either of its two objectives. Nevertheless, the Constituent General Assembly of 1813 made sovereign decisions that clearly paved the way for national independence. As for its constituent work, although it did not sanction a Magna Carta, constitutional projects were presented with an undeniable value as antecedents in the matter. Likewise, we stop at the analysis of the figure and thought of José Gervasio Artigas, undisputed precursor of federalism in the Río de la Plata.

Keywords: Constitutional History; 13th Year Constituent Assembly; Federalism; Artigas.

Resumo: No presente trabalho analisamos a obra e as circunstâncias históricas ao redor do primeiro Congresso argentino: a Assembléia Constituinte do Ano XIII. Seus objetivos eram a declaração de independência e 0 ditado de uma Constituição. Por dificuldades internas, a falta de uma representação popular genuína, juntamente com os sucessos que ocorreram simultaneamente na Europa, como a abdicação de Napoleão e 0 retorno ao trono de Espanha de Fernando VII, a Assembleia não conseguiu nenhum de seus dois objetivos. Não obstante, a Assembléia Geral Constituinte de 1813 tomou decisões soberanas que claramente abriram o caminho para a independência nacional. Em relação ao seu trabalho constituinte, embora não sancionasse uma Carta Magna, sim foram apresentados projetos constitucionais com um valor inegável como antecedentes na matéria. Da mesma forma, vamos nos concentrar na análise da figura e o pensamento de José Gervasio Artigas, precursor incontestado do federalismo no Rio da Prata. 
Palavras Chaves: História Constitucional; Assembléia Constituinte do Ano XIII; Federalismo; Artigas.

Résumé: Dans cet article, nous analysons le travail et les circonstances historiques qui ont entouré le premier Congrès argentin: I'Assemblée constituante de l'an XIII. Ses objectifs étaient la déclaration d'indépendance et la publication d'une constitution. En raison de difficultés internes, de l'absence d'une représentation populaire authentique, ajoutée aux événements survenus au même moment en Europe, tels que l'abdication de Napoléon et le retour sur le trône d'Espagne de Ferdinand VII, I'Assemblée n'a atteint aucun de ses deux objectifs. Néanmoins, I'Assemblée générale constituante de 1813 prit des décisions souveraines qui ouvraient clairement la voie à l'indépendance nationale. En ce qui concerne son travail constitutif, bien qu'elle n'ait pas sanctionné une Magna Carta, les projets constitutionnels étaient présentés avec une valeur indéniable comme toile de fond. De même, la figure et la pensée de José Gervasio Artigas, précurseur incontesté du fédéralisme dans le Río de la Plata, sont particulièrement analysées.

Mot-clés: Histoire constitutionnelle - Assemblée constituante de l'an XIII - Fédéralisme - Artigas.

\section{Introducción}

La formación institucional de la Argentina se nos presenta como el resultado de un complejo y arduo proceso político de marchas y contramarchas durante sus primeros cincuenta años de vida independiente.

Como nos enseña Demicheli, luego de la revolución de mayo de 1810 surgirán en el Río de La Plata dos métodos antagónicos encaminados a la organización del incipiente Estado, métodos que por sus propias características diferenciales los denomina: unilateral (o estatutario) y contractual (o sinalagmático). Así, el primero de ellos se hace efectivo mediante reglamentos orgánicos obligatorios, en tanto que el otro por medio de pactos políticos previos. ${ }^{2}$

2 DEMICHELI, Alberto, Formación Constitucional Rioplatense, Tomo III, Los Pactos en el Proceso de Organización, Depalma, Montevideo, 1955, pag. 7. 
Desde el movimiento libertario de 1810, Buenos Aires, antigua capital del virreinato, está llamada a tener un rol protagónico en el surgimiento de la nueva nación y pretenderá desde un principio imponer su autoridad mediante el dictado unilateral de diversos reglamentos y estatutos iniciales con alcance imperativos para todos. En franca oposición se levantará la figura de José Gervasio Artigas, "protector de los pueblos libres", quien propuso el método del pacto como forma de organización y unión nacional.

En la matriz misma de nuestro federalismo, los pactos fueron marcando el camino a través del tiempo hacia la tan ansiada unidad nacional, reconociendo la diversidad y el respeto por las autonomías provinciales. Tal es así que los constituyentes reunidos en el Congreso de Santa Fe en 1853 plasmaron en el preámbulo de nuestra Carta Magna que concurrían al mismo “...en cumplimiento de pactos preexistentes".

El término pacto proviene del latín pactum y significa "concierto o tratado entre dos o más partes que se comprometen a cumplir lo estipulado". De allí que el tratado o acuerdo político nos da la idea de entendimiento, negociación, libre aceptación de lo estatuido, en fin, de voluntad de arribar a coincidencias para el logro de fines comunes. ${ }^{3}$

Los sucesos de mayo de 1810 enfrentaron a los porteños con los pueblos del interior que, si bien aceptaron el fin del pacto colonial con España, descartaron de plano la nueva dependencia que les imponía Buenos Aires.

Frente a la revolución de mayo y el surgimiento de un nuevo gobierno patrio, la Banda Oriental reaccionó dividida. Mientras que Montevideo se inclinó por la defensa del Consejo de Regencia manteniendo los vínculos con la madre patria, la población del interior con Artigas a la cabeza se sumó a la causa revolucionaria. ${ }^{4}$

3 MORENO, Guillermo Raúl, En cumplimiento de pactos preexistentes. Organización institucional argentina (1820-1853). Editorial de la Universidad de La Plata (EDULP), La Plata, 2008, pag. 17.

4 Como sostiene Arteaga, "La población del interior, en cambio, se fue adhiriendo al juntismo en un movimiento que su jefe llamó "la admirable alarma", inicio de la revolución oriental 
Será el caudillo oriental quien se pondrá al frente de la corriente federal en el Río de La Plata y, enarbolando la bandera de las autonomías provinciales, se opondrá al centralismo porteño en los años que siguieron a la gesta emancipadora.

\section{La Logia Lautaro. Revolución del 8 de octubre de 1812. El Segundo Triunvirato}

A principios del año 1812 llegaba a Buenos Aires el teniente coronel de Caballería Don José de San Martín, quien luego de varios años al servicio de la corona española, solicitó su retiro para regresar a la tierra donde había nacido. Junto con él llegaron al Río de La Plata otros militares de marcada trayectoria en el ejército de la madre patria (Alvear, Zapiola, Chilavert, entre otros).

Al poco tiempo de llegar, San Martín, a quien se le reconoció su grado militar, se le encomendó la formación de un escuadrón de caballería de línea. Entre tanto que formaba e instruía personalmente a sus granaderos a caballo, San Martín junto a sus compañeros de viaje crearon la "Logia Lautaro", una entidad secreta que tuvo como propósito ejercer influencia en los medios militares y políticos de la Buenos Aires de entonces.

Poco se sabe de la Logia Lautaro, ya que su funcionamiento fue secreto y quedó oculto por voluntad de quienes la integraron. Se supone que fue establecida en Buenos Aires entre mayo y junio de 1812, funcionando en domicilios privados y que existían en la organización cinco grados en sus componentes. En los primeros se los iniciaba en los principios de fraternidad y mutua cooperación, pero en las jerarquías superiores se los advertía de los verdaderos objetivos de la logia: independencia y constitución. ${ }^{5}$

El 8 de octubre de 1812 se desató una revolución promovida por la logia Lautaro y la Sociedad Patriótica. ${ }^{6}$ La misma tendrá

en 1811. ARTEAGA, Juan José, Breve Historia Contemporánea del Uruguay", Fondo de Cultura Económica, Bs. As. 2008, pag. 44.

5 ROSA, José María, Historia Argentina, Juan J. Granda Editores, Bs. As, 1967, T II, pag. 364.

6 La Sociedad Patriótica, con Monteagudo a la cabeza, se constituyó como la cara pública y visible de la Logia Lautaro cuya actuación siempre estuvo oculta. 
por objetivo enderezar el rumbo de los acontecimientos: se disolvió el primer triunvirato y se procedió a formar un gobierno de transición, conocido luego como el "segundo triunvirato". Los electos fueron Juan José Paso, Nicolás Rodríguez Peña y Antonio Alvarez Jonte, a quienes se les encomendó como primera medida convocar a una asamblea soberana que finalmente organizara el país.

La Asamblea General Constituyente del año XIII claramente tendría dos objetivos: Declaración de independencia y dictado de una constitución. Así se desprende del propio decreto suscripto por el gobierno por medio del cual se convocó a elecciones de diputados a la Asamblea General. ${ }^{7}$

\section{Convocatoria a la Asamblea. Obra legislativa. Soberanía. Derechos individuales}

El decreto de convocatoria fue dado a conocer el 24 de octubre de 1812, expresándose el modo y la forma de la elección de los diputados que debían integrar la asamblea. La elección sería indirecta. Los gobernadores o tenientes pasarían orden a los alcaldes de barrio para que, citando a todos los vecinos libres y patriotas, se designe un elector a pluralidad de sufragios. Los electores designados debían concurrir al ayuntamiento del lugar para proceder a elección del diputado. Las votaciones serían públicas y a viva voz. ${ }^{8}$

El decreto también dejaba expresado la cantidad de diputados que debían concurrir a la Asamblea: cuatro por la capital; las demás capitales de provincias designarían dos y uno cada ciudad de su dependencia. En cuanto a los poderes que debían llevar los diputados, serían otorgados sin limitaciones.

\footnotetext{
7 “La Constitución que se sancione alentará la timidez de unos, contendrá la ambición de otros, acabará con la vanidad inoportuna, atajará pretensiones atrevidas, destruirá pasiones insensatas y dará fin a los pueblos la carta de sus derechos y al gobierno de sus obligaciones". Ver en GALLETTI, Alfredo, Historia Constitucional Argentina. Librería Editora Platense, La Plata, 1987, Tomo I, pag. 269.

8 Ver GALLETTI, Alfredo, Ob. Cit. Pag. 270.
} 
La Asamblea quedó formalmente inaugurada el 31 de enero de 1813 en la ciudad de Buenos Aires. Ese mismo día, según lo dispuesto por el bando del Poder Ejecutivo Provisorio, se resolvió que en la Asamblea "residía la representación y soberanía de las Provincias Unidas del Río de La Plata”. Esto significaba otorgarle el carácter de soberana, es decir, que la misma no reconocería autoridad superior alguna. Esta decisión, sumada a la fórmula de juramento de los diputados, donde se excluía toda mención a Fernando VII, nos señala la firme vocación de los hombres de entonces de romper los vínculos con la monarquía española. Ese mismo día fueron designadas las autoridades de la Asamblea: Carlos Alvear (presidente), Hipólito Vieytes y Valentín Gómez (secretarios).

La Asamblea del año XIII detentó el doble carácter de constituyente y legislativa. No logró ninguno de los objetivos que se propuso (Independencia y Constitución). Sin embargo, a la hora de analizar su labor como un antecedente en nuestra organización institucional, destacamos algunas decisiones tomadas que allanaron el camino hacia la independencia. Resulta innegable que sus actos fueron claramente legítimas expresiones de soberanía. Asimismo, como veremos seguidamente, los proyectos constitucionales presentados en la asamblea son valiosos aportes en el largo derrotero de nuestro país en su anhelo de contar con su primera Carta constitucional.

Si se toman en cuenta algunos decretos y resoluciones dictados por la Asamblea del año XIII desde el punto de vista de los derechos individuales, se llega a la conclusión que sus integrantes respondieron al pensamiento liberal surgido de las grandes revoluciones de finales del Siglo XVIII. Eran tiempos de consagrar derechos y garantías pertenecientes al ser humano por su condición de tal, que nace libre e igual a los demás, con derechos intransferibles que hacen a su propia esencia.

La Asamblea adoptó, entre otras, las siguientes medidas: estableció un sello oficial que tenía el diseño del actual escudo nacional; decretó tener como única marcha nacional la pieza musical compuesta por el diputado López y Planes la que se 
debería entonar en todos los actos públicos; mandó acuñar una moneda con la leyenda "Provincias Unidas del Río de La Plata, en unión y libertad"; declaró el 25 de mayo como día de fiesta cívica; abolió el mayorazgo, los títulos de nobleza, el uso de tormentos; declaró extinguido el tributo, la mita, la encomienda, el yanaconazgo y toda forma de servicio personal de los indios.

A su vez la Asamblea del año XIII es recordada por haber sancionado la ley de vientres, mediante la cual se declararon libres a todos los nacidos y que nacieran desde el 31 de enero de 1813, día de la instalación de la Asamblea. Dos días más tarde decretó que todos los esclavos de países extranjeros que del cualquier modo se introduzcan en territorio de las Provincias Unidas, pasarían a ser libres por el solo hecho de pisar su territorio. Sin embargo esta última iniciativa tuvo que ser dejada sin efecto tiempo después a partir de las presiones de Brasil que consideró como un acto hostil el propiciar la deserción de los negros de su territorio. ${ }^{9}$

Debemos destacar que la libertad de vientres no significó la abolición de la esclavitud. Recién en 1853, al sancionarse la Constitución Nacional se dispuso que "En la Nación Argentina no hay esclavos: los pocos que hoy existen quedan libres desde la jura de esta Constitución"10

\section{El federalismo. El pensamiento político de Artigas. Instrucciones Orientales}

José Gervasio Artigas nació en Montevideo en 1764. Era descendiente de una de las familias tradicionales fundadoras de esa ciudad ${ }^{11}$. Desde muy joven dejó la ciudad para ir al campo,

\footnotetext{
9 Ver CALA, Laura Alejandra, Asamblea del Año XIII: Comentarios de una breve compilación -Homenaje a sus 200 años. Publicado en Revista ANALES Nº 43 - Facultad de Cs. Jurídicas y Sociales. U.n.I.p. 2013. Pag. 19.

10 Art. 15 de la Constitución Nacional

11 Según nos cuenta Felix Luna, su abuelo había venido con el fundador de Montevideo a estas tierras. LUNA, Félix, Los Caudillos, Planeta, Bs. As. 1988, pag. 33.
} 
allí trabajará en estancias propias y ajenas. Al mismo tiempo ingresará al cuerpo de blandengues, una especie de policía rural para defender la campaña.

Cuando en mayo de 1810 se produce la destitución del Virrey Cisneros y la instalación de la primera junta en Buenos Aires, Artigas no dudó en ponerse del lado de los revolucionarios ofreciendo sus servicios al nuevo gobierno.

En poco tiempo Artigas pasará a ser el caudillo de mayor prestigio en la Banda Oriental y en las provincias litorales. Con su liderazgo y carisma personal infundirá un aliento popular a la revolución. Fue el primero en alzar su voz exigiendo que se declare formalmente la independencia de las provincias y se rompan definitivamente los vínculos con la corona de España.

Como ya lo hemos señalado, frente al centralismo porteño se opondrá la figura y el pensamiento de Artigas, inspirado en las enseñanzas de Montesquieu y el constitucionalismo de la revolución norteamericana. Propondrá que a través de una convención o pacto entre diversas entidades territoriales acuerden entre todas formar un nuevo Estado, manteniendo cada una su propia identidad.

Será el caudillo oriental el primero en reclamar en el Río de La Plata la existencia de gobiernos provinciales autónomos, que uniéndose entre sí mediante pactos recíprocos, logren entre todas las provincias del antiguo virreinato la formación de una verdadera unión federal.

Este pensamiento se verá reflejado claramente en las célebres "instrucciones orientales". Las instrucciones fueron una serie de directivas que llevaron los diputados de la Banda Oriental a la Asamblea general constituyente reunida en Buenos Aires.

El 5 de abril de 1813, Artigas convocó a las ciudades y villas de la Banda Oriental a un Congreso en Montevideo (luego conocido como el "Congreso Oriental de Peñarol" o "Congreso de Tres Cruces"). Fue allí donde el caudillo oriental pronunció una de sus frases más conocidas y que demuestran el verdadero sentido que para él tenían la soberanía popular y la representación 
política: "Mi voluntad emana de vosotros, y ella cesa por vuestra presencia soberana" sostuvo Artigas ante los asistentes al inaugurar formalmente el congreso.

Allí comunicará a los diputados intervinientes que la anunciada asamblea ya había comenzado a sesionar en Buenos Aires y que su reconocimiento había sido ordenado. El objetivo del congreso estuvo en decidir si se reconocía la asamblea, y de ser así, designar los diputados que representarían a la Banda Oriental en la misma. "La Asamblea tantas veces anunciada empezó ya sus sesiones en Buenos Aires...su reconocimiento nos ha sido ordenado. Resolver sobre este particular ha dado motivo a esta congregación...examinad si debéis reconocer la Asamblea por obedecimiento o por pacto". ${ }^{12}$

Una vez resuelto el reconocimiento de la Asamblea, se procedió a elegir los diputados que serían enviados a Buenos Aires en representación de la provincia oriental. ${ }^{13}$

\section{Las instrucciones de Artigas (13 de abril de 1813) ${ }^{14}$}

Los diputados de las provincias concurrieron a la Asamblea Constituyente del año XIII munidos de "instrucciones" que concretaban las aspiraciones de sus representados. Ya el decreto de convocatoria surgido del segundo triunvirato $(24 / \mathrm{X} / 1812)$ facultaba expresamente a los pueblos a conferir instrucciones a sus diputados. Esto era una práctica habitual de la época. Los diputados en principio debían ajustarse a las directivas o instrucciones en el desempeño de sus funciones de acuerdo a la voluntad de quienes estaban representando.

\footnotetext{
12 ROSA, José María, ob. cit. T III, pag. 59.

13 En total fueron elegidos seis diputados: Dámaso Larrañaga y Mateo Vidal por Montevideo; Dámaso Fonseca por Maldonado; Felipe Cardozo por Canelones; Martín Salcedo por San José y Francisco Bruno de Rivarola por Soriano. ROSA, José María, ob. cit. Pag. 60.

14 Sostiene la Prof. ARAMBURÚ que en realidad se conocen tres instrucciones emanadas del pueblo oriental: las del 5 y 6 de abril; las de Artigas del 13 de abril y las de Soriano. Ver ARAMBURÚ, Julia Edith, Artigas y las instrucciones orientales del 13 de abril de 1813, ANALES Nº 41 - Facultad de Cs. Jurídicas y Sociales. U.n.I.p. 2011, pag. 358.
} 
En las instrucciones orientales se resume el pensamiento político de Artigas. Sus ideas básicas serán: independencia, república y federación.

Para su elaboración, el caudillo oriental tomó diversas fuentes vinculadas con el proceso de revolución norteamericana (Artículos de Confederación de 1781; Constitución de Filadelfia de 1787; las enmiendas constitucionales norteamericanas dictadas hasta 1811; Constituciones territoriales de los Estados norteamericanos) ${ }^{15}$. El autor no copió literalmente estos textos, sino que, mediante una inteligente selección de disposiciones, sumado a conclusiones propias surgidas del conocimiento de su realidad y su tiempo, le permitieron la elaboración de las célebres instrucciones: ${ }^{16}$

Instrucciones que se dieron a los representantes del pueblo oriental, para el desempeño de su cargo en la Asamblea Constituyente fijada en la ciudad de Buenos Aires. Delante de Montevideo, 13 de abril de 1813. ${ }^{17}$

Primeramente pedirá la declaración de la independencia absoluta de estas colonias, que ellas están absueltas de toda obligación de fidelidad a la corona de España y familia de los Borbones y que toda conexión política

\footnotetext{
15 Nos cuenta Demicheli que a fines de 1811 Artigas recibe la versión en castellano de diferentes constituciones norteamericanas, publicadas poco antes en Filadelfia por el venezolano Manuel García Sena. Al final del libro, el traductor inserta: la declaración de independencia del 4 de junio de 1776; Ios Artículos de Confederación y perpetua unión; la Constitución de los Estados Unidos de 1787; las primeras doce enmiendas a la Constitución norteamericana; la Constitución de Massachusetts, la Constitución de Connecticut; la Constitución de New-Jersey; la Constitución de Pennsylvania y la Constitución de Virginia. DEMICHELI, Alberto, Formación Nacional Argentina, Derecho Público Preexistente, Pactos Interprovinciales y su constitucionalización. Depalma, Bs. As. 1971, Tomo I pag. 77.

16 De acuerdo a lo informado en la página web oficial de la Presidencia de la República Oriental del Uruguay existen al día de hoy por lo menos cinco manuscritos originales de las "instrucciones del año XIII", de los cuales uno de ellos es una copia autenticada por el propio Artigas y se encuentra en el Museo histórico Nacional de dicho país.

17 Texto según documento original que obra en el Archivo General de la Nación de Montevideo. Fondo del ex Archivo y Museo de Hist. Nac., Caja 196; carpeta IV, año 1813. Citado por DEMICHELI, Alberto, Ob. Cit. Pag. 411.
} 
entre ellas y el Estado de la España, es y debe ser totalmente disuelta.

Art. 2 - No admitirá otro sistema que el de Confederación para el pacto recíproco con las provincias que formen nuestro Estado.

Art. 3 - Promoverá la libertad civil y religiosa en toda su extensión imaginable.

Art. 4 - Como el objeto y fin del Gobierno debe ser conservar la igualdad, libertad y seguridad de los ciudadanos y de los Pueblos, cada Provincia formará su gobierno bajo esas bases, a más del Gobierno Supremo de la Nación."

Art. 5 - Así este como aquel se dividirán en poder legislativo, ejecutivo y judicial."

Art. 6 - Estos tres resortes jamás podrán estar unidos entre sí y serán independientes en sus facultades."

Art. 7 - El Gobierno Supremo entenderá solamente en los negocios generales del Estado. El resto es peculiar al gobierno de cada Provincia.

Art. 8 - El territorio que ocupan estos Pueblos de la costa oriental del Uruguay hasta la fortaleza de Santa Teresa, forma una sola Provincia, dominante: La Provincia Oriental.

Art. 9 - Que los siete pueblos de Misiones, los de Batovi, San Rafael y Tacuarembó, que hoy ocupan injustamente los portugueses y a su tiempo deben reclamarse, serán en todo tiempo territorio de esta Provincia.

Art. 10 - Que esta Provincia por la presente entra separadamente en una firme liga de amistad con cada una de las otras, para su defensa común, seguridad de su libertad y para su mutua y general felicidad, obligándose a asistir a cada una de las otras contra toda violencia o ataques hechos sobre ellas, o sobre algunas de ellas, por motivo de religión, soberanía, tráfico o algún otro pretexto cualquiera que sea.

Art. 11 - Que esta Provincia retiene su soberanía, libertad e independencia, todo poder, jurisdicción y derecho que no es delegado expresamente por la Confederación a las Provincias Unidas juntas en Congreso. 
Art. 12 - Que el puerto de Maldonado sea libre para todos los buques que concurran a la introducción de efectos y exportación de frutos, poniéndose la correspondiente aduana en aquel pueblo; pidiendo al efecto se oficie al comandante de las fuerzas de S.M.B. sobre la apertura de aquel puerto para que proteja la navegación o comercio de su nación.

Art. 13 - Que el puerto de la Colonia sea igualmente habilitado en los términos prescriptos en el artículo anterior.

Art. 14 - Que ninguna tasa o derecho se imponga sobre artículos exportados de una provincia a otra; ni que ninguna preferencia se dé por cualquiera regulación de comercio o renta, a los puertos de una provincia sobre los de otra; ni los barcos destinados de esta provincia a otra serán obligados a entrar, a anclar o pagar derecho en otra.

Art. 15 - No permita se haga ley para esta Provincia sobre bienes de extranjeros que mueren intestados, sobre multas y confiscaciones que se aplicaban antes al Rey y sobre territorios de éste, mientras ella no forma su reglamento y determine a qué fondos deben aplicarse, como única al derecho de hacerlo en lo económico de su jurisdicción.

Art. 16 - Que esta Provincia tendrá su constitución territorial; y que ella tiene el derecho de sancionar la general de las Provincias Unidas que forme la Asamblea Constituyente.

Art. 17 - Que esta Provincia tiene derecho para levantar los regimientos que necesite, nombrar los oficiales de companía, reglar la milicia de ella para la seguridad de su libertad, por lo que no podrá violarse el derecho de los pueblos para guardar y tener armas.

Art. 18 - El despotismo militar será precisamente aniquilado con trabas constitucionales que aseguren inviolable la soberanía de los Pueblo

Art. 19 - Que precisa e indispensable sea fuera de Buenos Aires donde resida el sitio del Gobierno de las Provincias Unidas. 
Art. 20 - La constitución garantirá a las Provincias Unidas una forma de gobierno republicana y que asegure a cada una de ellas de las violencias domésticas, usurpación de sus derechos, libertad y seguridad de su soberanía, que con la fuerza armada intente alguna de ellas sofocar los principios proclamados. Y así mismo prestaría. toda su atención, honor, fidelidad y religiosidad, a todo cuanto crea, o juzgue, necesario para preservar a esta Provincia las ventajas de la libertad, y mantener un gobierno libre, de piedad, justicia, moderación e industria. Para todo lo cual, etc.

Delante de Montevideo, 13 de abril de 1813.

A manera de síntesis, las instrucciones contenían los siguientes lineamientos generales: declaración de independencia absoluta de España; instauración de un sistema de confederación; libertad civil y religiosa; igualdad, libertad y seguridad; separación e independencia de poderes (tanto en los gobierno de las provincias como en de la Nación); las provincias ejercerían todo el poder no delegado a la Nación; consagración de libertades económicas; fijación de límites al territorio de la Banda Oriental; Apertura de dos puertos orientales (Colonia y Maldonado); instauración de una liga de amistad, ofensiva y defensiva entre todas las provincias; cada provincia dictaría su propia constitución y participaría junto con las demás de sancionar una constitución nacional; el autoritarismo militar se debía aniquilar con trabas constitucionales; la capital no podía residir en Buenos Aires; forma republicana de gobierno.

La Asamblea rechazó los poderes de los diputados artiguistas electos aduciendo falta de legalidad y cuestiones formales: "diplomas absolutamente nulos por incontestables principios"18. Tal afirmación no hizo más que ocultar una maniobra del gobierno para impedir la participación de los representantes de la Banda Oriental en la Asamblea.

18 Ver en PALACIO, Ernesto, Historia de la Argentina 1515-1943, A. Peña Lillo Editor, Bs. As. 1979, pag. 205. 


\section{Proyectos Constitucionales}

La Asamblea fue convocada como "general constituyente", es decir con el objetivo de sancionar una Constitución. Como ya lo adelantáramos anteriormente, dicho propósito no fue alcanzado y ello se debió, entre otras razones, por no haberse declarado previamente la independencia de España.

No se sancionó una Constitución en aquella oportunidad, pero si fueron presentados en el seno de la Asamblea cinco proyectos constitucionales de innegable importancia como antecedentes en el largo proceso de organización institucional de nuestro país. Estos fueron:

1) Proyecto de la Comisión Oficial (unitario)

2) Proyecto de la Sociedad Patriótica (unitario)

3) Proyecto anónimo (unitario)

4) Proyecto de Constitución Federal para las Provincias Unidas (federal)

5) Proyecto de Constitución Territorial para la Provincia Oriental (federal)

\section{1) Proyecto de la Comisión Oficial ${ }^{19}$}

Este proyecto fue redactado por una comisión especial designada por la propia asamblea ${ }^{20}$

Constaba de 276 artículos distribuidos en 22 capítulos. ${ }^{21} \mathrm{Si}$ bien fue presentado, no llegó a tratarse.

No tiene preámbulo. Comienza con tres grandes declaraciones: "Las provincias del Río de la Plata, forman una República

\footnotetext{
19 Se puede acceder al texto completo en https://archivos.juridicas.unam.mx/www/bjv/ libros/5/2113/9.pdf

20 La misma estaba formada por Chorroaquín, Gómez, Vieytes, Herrera, Somellera y Agrelo. Por renuncia de Chorroaquín, se sumará Posadas. SANCHEZ VIAMONTE, Carlos, Historia Institucional de Argentina, Fondo de Cultura Económica, México- Bs. As. 1948, pag. 111.

21 Tiene la particularidad que los artículos no son correlativos, es decir, no tienen una numeración corrida. Se enumeran capítulo por capítulo.
} 
libre e independiente"; "La soberanía del Estado reside esencialmente en el pueblo"; "El pueblo es la reunión de todos los hombres libres de la República". Adopta a la católica como religión de Estado (al mismo tiempo garantiza la libertad de culto). Consagra los "derechos del ciudadano" (igualdad ante la ley, libertad civil, seguridad individual). Adopta la clásica división de los poderes constituidos: Poder Legislativo, Ejecutivo y Judicial

El Poder Legislativo era bicameral, compuesto por un Senado y una Cámara de Representantes; El Poder Ejecutivo colegiado compuesto por tres miembros (triunvirato) elegidos por ambas cámaras legislativas con una duración de seis años en sus cargos. En cuanto al Poder Judicial, el proyecto disponía que el mismo debía ser independiente; que los jueces conservaban sus cargos mientras obraran bien (inamovilidad) y que habría una Corte Suprema de Justicia para todo el Estado, tribunales superiores en cada provincia, jueces letrados en cada partido y alcaldes en todos los pueblos.

\section{2) Proyecto de la Sociedad Patriótica ${ }^{22}$}

Fue elaborado por los miembros más representativos de la Sociedad Patriótica ${ }^{23}$. Se componía de 213 artículos, divididos en 25 capítulos. Inspirado en la Constitución francesa de 1795 y la norteamericana de 1787. Carece de un preámbulo. Denomina al Estado como Provincias de la América del Sur. Dedica un capítulo a los derechos del hombre (vida, honra, libertad, seguridad, igualdad y propiedad). Adopta como religión de Estado a la católica ${ }^{24}$. Contiene disposiciones referidas a la ciudadanía. Adopta la división de poderes: Poder Legislativo bicameral (cámara de representantes y cámara de senadores); Poder Ejecutivo unipersonal a cargo de un Presidente con tres

\footnotetext{
22 Se puede acceder a su texto completo en https://archivos.juridicas.unam.mx/www/bjv/ libros/5/2113/6.pdf

23 Monteagudo, Larrea, Planes, Valle y Cosme Argerich.

24 Según establecía su artículo 12, "La Religión Católica es y será siempre la del Estado".
} 
años de duración en funciones, también preveía la figura de un vicepresidente quien ejercería la presidencia del Senado. Dedica un capítulo al "gobierno ejecutivo de cada provincia". Tal vez sea en estas disposiciones donde se muestre más claramente la concepción centralista de este proyecto constitucional, en donde las provincias no tenían ningún derecho, ni siquiera la de nombrar a sus propias autoridades. Se estableció que en cada provincia habría un prefecto, nombrado por el Poder Ejecutivo Nacional el que "deberá cumplir en ella todas las órdenes que le comunicará para su ejecución el Presidente”. Establecía un Supremo Poder Judicial compuesto por nueve magistrados, también contenía disposiciones referidas al poder judicial en cada provincia. Contaba con una sección destinada a la libertad de imprenta y otra a las municipalidades.

\section{3) Proyecto anónimo 25}

Se desconoce la autoría del proyecto. Se supone que se trata de un trabajo realizado por algún integrante de la Asamblea teniendo en cuenta y tomando en parte los otros dos proyectos anteriores: el de la Comisión Oficial y el de la Sociedad patriótica. Viene a completar la serie de proyectos unitarios presentados en la Asamblea del año XIII. Se compone de 187 artículos divididos en 13 capítulos.

A diferencia de los dos anteriores, este proyecto comienza con un preámbulo bajo el título "Declaración de los derechos y deberes del hombre en sociedad". Denomina al Estado como "Provincias Unidas del Río de La Plata", demarca su territorio, adopta a la católica como la religión del Estado; sigue la división tripartita de los poderes constituidos: Poder Legislativo Bicameral (Senado y Sala de Representantes); El Poder ejecutivo en manos de un Directorio Ejecutivo de tres miembros (triunvirato) elegidos por el poder legislativo. El Poder Judicial compuesto

\footnotetext{
25 RAVIGNANI, Emilio, Asambleas Constituyentes Argentinas, seguidas de los textos constitucionales, legislativos y pactos interprovinciales que organizaron políticamente la Nación, Talleres S.A. Jacobo Peuser Ltda. Bs. As. 1939 T VI, 2da parte pag. 623.
} 
por un Supremo Tribunal de Justicia, Tribunales Superiores de provincia y jueces criminales y civiles para todo el país. Este proyecto no contiene disposición alguna referida a las provincias, ni siquiera las menciona.

\section{4) Proyecto de Constitución Federal para las Provincias Unidas ${ }^{26}$}

Este proyecto de Constitución federal contiene el pensamiento de Artigas volcado en las instrucciones orientales que ya hemos analizado anteriormente. Tanto el presente, como el proyecto territorial elaborado por la Banda Oriental, son complementarios. Uno fue pensado para organizar el Estado Nacional (constitución nacional) y el otro para uno de los estados provinciales que lo integraban (constitución provincial).

El proyecto de constitución de carácter federal para las Provincias Unidas de la América del Sud se denomina "Artículos de confederación y perpetua unión entre las provincias de Buenos Aires, Santa Fe, Corrientes, Paraguay, Banda Oriental del Uruguay, Córdoba, Tucumán, etc.”. Resulta clara que la fuente de inspiración fueron los Artículos de Confederación y Unión Perpetua de los Estados Unidos de Norteamérica de $1777^{27}$ y la Constitución norteamericana sancionada en Filadelfia en $1787 .{ }^{28}$

A nuestro criterio, este proyecto constitucional presentado por los diputados artiguistas en la Asamblea del Año III, si bien no fue tratado ni aprobado, resulta fuente indubitable de la Constitución Nacional sancionada en 1853.

26 RAVIGNANI, Emilio, Ob. Cit. T VI, 2da parte, pag. 633.

27 Constituyeron el primer documento de gobierno de los Estados Unidos, aprobados en 1777 y ratificados en 1778 . Se establece una confederación entre los trece estados independientes para la defensa común, seguridad de sus libertades y bienestar general y recíproco. En 1787 la confederación se extinguirá para dar paso al primer estado federal moderno con la constitución de ese mismo año, que adoptará la forma de gobierno republicana presidencialista y la forma de estado democrático y federal. Ver BIDART CAMPOS, Germán, Manual de Historia Política, Ediar, Bs. As. 1997, pag. 224.

28 A su vez, toma principios económicos de la constitución de Virginia y de la de Massachusetts las bases del constitucionalismo local. También el proyecto contiene los derechos incluidos en las diversas enmiendas a la constitución norteamericana hasta 1811. 
De acuerdo a este proyecto constitucional, cada provincia retenía su soberanía, libertad e independencia y todo poder, jurisdicción y derecho que no fuera expresamente delegado. Las provincias entraban en una liga de amistad para la defensa común y para su mutua y general felicidad. Se obligaban a asistirse entre ellas en caso de violencia o ataques. ${ }^{29}$ Estableció el principio de igualdad absoluta entre todos los habitantes de las distintas provincias. ${ }^{30}$

En cuanto a la organización de los poderes, consagró un Poder Legislativo Bicameral, con dos cámaras separadas: una Sala de Representantes (diputados de la Nación, elegidos por el pueblo de las provincias por dos años, en proporción de uno por cada 20.000 habitantes y debían ser mayores de 25 años) y un Senado compuesto por dos senadores por provincia mayores de 30 años. Los legisladores serían remunerados por el tesoro nacional y no podrían ser arrestados por sus discursos o debates, tampoco podían recibir empleos ni funciones de otros poderes. Este proyecto es el primero en organizar un Congreso federal siguiendo el modelo norteamericano, el que luego tendrá su consagración definitiva en la Constitución de 1853.

El Poder Ejecutivo estaba en manos de un "presidente", quien duraba dos años en su cargo sin poder ser reelegido. Este proyecto estableció un curioso mecanismo rotativo de designación: se debía sortear un candidato entre todas las provincias. La provincia que salía beneficiada debía ser excluida del siguiente sorteo, para de esta forma, todas pudieran nombrar al presidente de la república. ${ }^{31}$

29 Art. 3. Ver RAVIGNANI, Emilio, Asambleas constituyentes argentinas, Ob. cit. T VI, 2da parte, pag. 634.

30 El art. 4 estableció que para asegurar la unión entre las distintas provincias, los habitantes libres de cada una de ellas tenían el privilegio e inmunidades inherentes a los ciudadanos de las demás, libre entrada en todas las provincias y mismos privilegios con referencia al tráfico y al comercio y mismos deberes y restricciones (igualdad civil y económica entre los habitantes de las distintas provincias). RAVIGNANI, Emilio, Asambleas constituyentes argentinas, Ob. cit. T VI, 2da parte, pag. 634

31 Ver art. 41 del proyecto. 
Fueron establecidos principios del debido proceso: inviolabilidad de "casas, papeles y efectos"; prohibición de arresto sin orden previa (art. 47); imposibilidad de doble juzgamiento por el mismo hecho (art. 48); protección de la vida, libertad y bienes (art. 48), juez natural (art. 50); prohibición de penas crueles (art. 51).

Se instituye un poder judicial doble; uno para los asuntos de carácter nacional (federal) y otro para las cuestiones de las provincias (organizado en la constitución provincial). De la justicia federal este proyecto faculta al Congreso en su art. 35 la creación de tribunales inferiores a la Corte Suprema de Justicia. De acuerdo a los principios clásicos, ni el Poder Legislativo ni el Poder Ejecutivo jamás podrán ejercer funciones propias del Poder Judicial (art. 63).

Asimismo, el proyecto establecía la posibilidad de que la Constitución pudiera ser reformada. Para que ello ocurriera debería declararse la necesidad de la reforma por las dos terceras partes de ambas cámaras o a solicitud de las dos terceras partes de las legislaturas provinciales (art. 62).

La última parte está dedicada a los "puntos principales de la Constitución provincial”. Allí, en cuatro artículos, quedan formuladas las bases sobre las cuales las provincias dictarían sus respectivas constituciones locales (soberanía popular, igualdad en el ejercicio de las funciones públicas, libertad de comicios y elecciones, entre otras).

\section{5) Proyecto de Constitución Territorial para la Provincia Oriental ${ }^{32}$}

Como ya quedara expresado con anterioridad, el pensamiento federal de Artigas se ve reflejado en dos proyectos de Constitución (uno nacional y otro provincial) que necesariamente deben

\footnotetext{
32 Se puede acceder a su texto completo en DEMICHELI, Alberto, Formación Nacional Argentina, Derecho Público Preexistente, Pactos Interprovinciales y su Constitucionalización, Depalma, Bs.As. 1971, Tomo I, pag. 415.
} 
complementarse. De allí que los diputados orientales además del Proyecto de Constitución federal para las Provincias Unidas, llevaron a la Asamblea un proyecto de Constitución territorial para la Banda Oriental.

El proyecto comienza con un capítulo dedicado a los derechos y declaraciones de carácter general. Allí se establecen los "derechos naturales" (vida, libertad, seguridad, felicidad); libertad de cultos; enseñanza primaria obligatoria y gratuita; derecho a la igualdad; derecho de la provincia oriental a gobernarse como un "Estado libre, soberano e independiente" en ejercicio de todo el poder no delegado a las Provincias Unidas. Se estableció que el gobierno es instituido para el bien común y felicidad de los pueblos y no para el interés privado de ningún hombre ni familia alguna; se instauró el derecho de acceso a la justicia en defensa de la persona o la propiedad; se consagraron las reglas del debido proceso; libertad de imprenta; elecciones libres, independencia del poder judicial y división de poderes. ${ }^{33}$

Seguidamente, el proyecto se refiere a la parte orgánica de la Constitución. Adopta la clásica división tripartita de los poderes constituidos. Poder Legislativo bicameral, compuesto por una Sala de Representantes y un Senado. Poder Ejecutivo a cargo de un "Gobernador de la Provincia Oriental del Uruguay"34, elegido por ambas cámaras y con una duración de un año en su cargo. El Poder Judicial estaría a cargo de los cabildos de las ciudades y villas. El proyecto contemplaba una justicia rápida, eficiente y gratuita. ${ }^{35}$ Por último destacamos la firme intención, plasmada en el proyecto, de fomentar la enseñanza media y superior. ${ }^{36}$

\footnotetext{
33 Ver Capítulo 1, arts. 1 a 21 del proyecto.

34 Capitulo 4, art. 1 del proyecto.

35 En estos términos se refiere GALLETTI, al analizar el poder judicial en este proyecto de constitución territorial. Ver GALLETTI, Alfredo, Ob. Cit. Pag. 306. Por nuestra parte creemos encontrar algo referido a la gratuidad del proceso judicial en el art. 8 del capítulo 5 del proyecto bajo el título "Poder Judiciario", en donde se establece la prohibición de papel sellado para pleitos.

36 El art. 5 del Capítulo 5 textualmente reza: “Art. 5-[Enseñanza media y superior] Y respecto a que nuestros sabios y piadosos europeos-españoles nos han mezquinado las artes, ciencias
} 


\section{EI Directorio. Sublevación de Fontezuelas. Disolución de la Asamblea}

En enero de 1814, la Asamblea decidió la concentración del poder ejecutivo en una sola persona creando el cargo de Director Supremo de las Provincias Unidas y declarando abolido el triunvirato. Así, en su sesión del 22 de enero de 1814 fue designado para el cargo Gervasio Antonio de Posadas, quien desempeñó sus funciones hasta su renuncia un año mas tarde el 9 de enero de 1815. El Director estaría acompañado por un Consejo de Estado integrado por nueve miembros encargados de asistirlo y asesorarlo en los asuntos de gobierno.

Los acontecimientos en Europa ante las derrotas sufridas por Napoleón en sus campañas y el inminente regreso de monarca Fernando VII al trono de España, quien se suponía, no dudaría en sofocar las revoluciones americanas, llevaron a la Asamblea a la concentración del gobierno en una sola persona. A esta delicada situación externa se sumaba las derrotas del ejército patriota en las batallas de Vilcapugio y Ayohuma. ${ }^{37}$

Entre tanto, la figura de Artigas se había consolidado en la Banda Oriental y en las provincias del litoral, convirtiéndose en un verdadero caudillo entre sus seguidores. Su prestigio y liderazgo indiscutido en las poblaciones encontraba fundamento en su espíritu localista, en su sentimiento de libertad contra sus

\footnotetext{
y bellas literaturas, con el fin depravado de que viviéramos en la vegetación de la oscuridad, ignorancia y desinterés de las ventajas que contribuyen al gran beneficio de los pueblos, preservación de sus derechos y libertad: será una ley precisa para el poder legislativo y demás magistrados presentes y venideros de esta provincia, el fomentar y levantar los seminarios para las ciencias, artes, aulas de gramática, filosofía, matemáticas y lenguas; fomentar las sociedades (privadas) y públicas e instrucciones para la promoción de la agricultura, comercio, oficios, manufacturas e historia natural del país, y todo afectos social y sentimiento generosos que acrediten las virtudes de un pueblo bien civilizado entre las Naciones cultas". Ver en DEMICHELI, Alberto, Formación Nacional Argentina, Derecho Público Preexistente, Ob. Cit. Pag. 430.

37 Batalla de Vilcapugio, el ejercito de Belgrano es derrotado por los realistas al mando de Pezuela el 1 de octubre de 1813. En Ayohuma, Belgrano es derrotado por segunda vez por el ejercito realista el 14 de noviembre de 1813 dando por finalizada la segunda expedición auxiliadora al Alto Perú.
} 
enemigos realistas y portugueses, como así también en su firme postura contra la política centralista de Buenos Aires. La sola idea de una federación propuesta por Artigas resultaba para los hombres del gobierno una propuesta anárquica, bárbara $o$ salvaje, opuesta al criterio llevado adelante por los dirigentes porteños desde el inicio de la revolución. Por todo ello, es que no transcurrió mucho tiempo para que las relaciones entre las autoridades porteñas y Artigas llegaran a deteriorarse y entraran en una franca tensión. A tal punto llegará dicho enfrentamiento que Posadas, al asumir como Director, lo declaró infame, traidor y enemigo de la Patria, lo puso fuera de la ley y ofreció recompensa a quien lo entregara vivo o muerto.

En junio de 1814 cae Montevideo, último reducto realista en el Río de la Plata. Será el tiempo de Artigas que, instalado hacia el litoral del río Uruguay en su campamento "La Purificación”, gobernará su territorio hasta que se produzca la invasión portuguesa de la Provincia Oriental. El caudillo, que comienza a ser llamado el "protector de los pueblos libres" se encuentra en la cúspide de su carrera política. Comienza a recibir apoyo de los pueblos de las provincias litorales, produciéndose una verdadera expansión del federalismo artiguista por toda la región.

Durante su breve gobierno, Artigas se mostró preocupado por la situación de la campaña oriental: inseguridad, disminución de la riqueza ganadera y latifundios improductivos. En este contexto da a conocer el 10 de septiembre de 1815 el "Reglamento de Tierras", ${ }^{38}$ un documento de gran trascendencia política que contiene aspectos sociales, económicos y productivos. En él se propone un proceso de distribución de tierras entre los más vulnerables. "Negros libres, zambos, indios, criollos pobres, viudas pobres con hijos" podrían verse beneficiados

38 El documento llevaba el título de "Reglamento Provisorio de la Provincia Oriental para el fomento de la Campaña y seguridad de sus Hacendados". Se puede acceder al mismo en Biblioteca Virtual Universal, http://www.biblioteca.org.ar/libros/158184.pdf. También se puede ampliar en ROJAS, Edgardo, Historia Constitucional. Uso alternativo del Derecho y Reglamento Provisorio de 1815 del Protector de los Pueblos Libres, Revista Derechos en Acción, Año 2 (2017), Verano 2017/2018, pag. 39/48, https://revistas.unlp.edu.ar/ReDeA/article/view/2916/3082. 
con la asignación de tierras para ser trabajadas propendiendo a la felicidad de la provincia y de sus habitantes. ${ }^{39}$ Será en el artículo 6 del Reglamento de Tierras donde quedará plasmada una de las frases más famosas del ideario artiguista: "los más infelices serán los más privilegiados". ${ }^{40}$

\section{La Liga de los Pueblos Libres. Congreso de Oriente (1815)}

El 29 de junio de 1815 se reunieron en el llamado Congreso de Oriente en Arroyo de la China (actual ciudad de Concepción del Uruguay, provincia de Entre Ríos) los representantes de las provincias que respondían al caudillo oriental. Allí concurrieron Misiones, Córdoba, Santa Fe, Entre Ríos, Corrientes y la Banda Oriental. Ese mismo día quedó conformada una alianza federal, que de hecho ya existía, conocida como la "Liga de los Pueblos Libres" bajo el protectorado de Artigas. Su primer acto fue declarar solemnemente la independencia de la monarquía española. ${ }^{41}$

\footnotetext{
39 Vemos como de manera incipiente ya se plantea y se reconoce una suerte de tutela diferenciada ante situaciones de vulnerabilidad. Ampliar en CABRAL, Pablo Octavio, La Ley $n^{\circ} 26.854$ de medidas cautelares contra el Estado Nacional. Una nueva legislación que reconoce tutelas procesales diferenciales en materia ambiental. Revista Federal de Derecho - número 1. Noviembre de 2017 (8-11-2017) IJ-CDLXXXII-868.
}

40 El artículo $6^{\circ}$ textualmente rezaba: "Por ahora el señor alcalde provincial y demás subalternos se dedicarán a fomentar con brazos útiles la población de la campaña. Para ello revisará cada uno, en sus respectivas jurisdicciones, los terrenos disponibles; y los sujetos dignos de esta gracia con prevención que los más infelices serán los más privilegiados. En consecuencia, los negros libres, los zambos de esta clase, los indios y los criollos pobres, todos podrán ser agraciados con suertes de estancia, si con su trabajo y hombría de bien propenden a su felicidad, y a la de la provincia". En tanto que el artículo $7^{0}$ disponía: "Serán también agraciadas las viudas pobres si tuvieren hijos. Serán igualmente preferidos los casados a los americanos solteros, y estos a cualquier extranjero".

41 Como señala José María Rosa "no se llevaron actas del Congreso de Oriente, o fueron destruidas. Sus resoluciones se inducen de la correspondencia de Artigas y sus integrantes". ROSA, José María, Historia Argentina, Ob. Cit. Tomo III, pag. 144. Es por ello que no existiría certeza de tal declaración de independencia. Señala 0 'Donnell que el propio Artigas al enterarse de la declaración del Congreso de Tucumán un año mas tarde, le escribe una carta al Director Supremo Juan Martín de Pueyrredón recordándole que "Ha más de un año que la Banda Oriental enarboló su estandarte tricolor y juró su independencia absoluta y respectiva. 
La liga federal de 1815 impondrá en nuestro país no solo sus principios federativos, sino también la técnica de los pactos interprovinciales como base previa a toda posible organización nacional.

En honor a la verdad histórica, debemos destacar que Artigas siempre rechazó la idea de independizar a la Banda Oriental. Muy por el contrario sostuvo desde los inicios de la revolución la idea de una provincia federal integrante de una confederación con el resto de las Provincias Unidas del Río de La Plata. Años mas tarde, con Artigas exiliado en Paraguay y retirado definitivamente de la escena política, se producirá en 1828 el surgimiento de la República Oriental del Uruguay como consecuencia del Tratado Preliminar de paz firmado con el Imperio del Brasil. Convenio éste, que pondría fin a la guerra suscitada entre ambos países en la disputa por el territorio oriental. Así, lejos del genuino sentimiento de Artigas y del pueblo de la Banda Oriental, esa provincia se escindirá definitivamente para convertirse en un nuevo Estado en el Río de La Plata, sancionando su primera constitución dos años mas tarde en $1830 .{ }^{42}$

El 9 de enero de 1815 Posadas presenta la renuncia a su cargo de Director Supremo. Ese mismo día la Asamblea designó

Lo hará V.E. presente al Soberano Congreso para su Superior conocimiento". Ver O’DONNELL, Pacho, 1815, La primera declaración de independencia argentina, Editorial Aguilar.

42 Los representantes orientales reunidos en el Congreso de La Florida el 25 de agosto de 1825, declararon solemnemente la independencia del Imperio del Brasil, para luego, un día más tarde, proclamar la unión con el resto de las provincias argentinas: "La H. Sala de Representantes de la Provincia Oriental del Río de la Plata en virtud de la soberanía ordinaria y extraordinaria que legalmente reviste para resolver y sancionar todo cuanto tienda a la felicidad de ella, declara: que su voto general, constante, solemne y decidido es, y debe ser, por la unidad con las demás Provincias Argentinas a que siempre perteneció por los vínculos más sagrados que el mundo conoce. Por tanto, ha sancionado y decreta por ley fundamental la siguiente: Oueda la Provincia Oriental del Río de la Plata unida a las demás de este nombre en el territorio de Sud América, por ser la libre y espontánea voluntad de los Pueblos que la componen, manifestada con testimonios irrefragables y esfuerzos heroicos desde el primer período de la regeneración política de dichas Provincias. Dado en la Sala de Sesiones de la Representación Provincial, en la villa de San Fernando de la Florida, a los veinticinco días del mes de agosto de mil ochocientos veinticinco". RAVIGNANI, Emilio, Asambleas Constituyentes argentinas, Ob. Cit. Tomo VI, 2da. Parte, pag. 166. (el resaltado me pertenece). 
al joven General Carlos María de Alvear para reemplazarlo. Su gobierno fue muy breve, tan solo estará tres meses en funciones.

Alvear intentará un acuerdo con Artigas quien se opondrá a un entendimiento con las nuevas autoridades centrales. Como el artiguismo no quiere pactar, entonces decidió enfrentarlo. Alvear tomó la determinación de enviar un ejército al mando del brigadier Ignacio Álvarez Thomas para enfrentar a las tropas de Artigas en Santa Fe. Pero ocurrió que en el trayecto, al arribar a la posta de Fontezuelas el 3 de abril de 1815, la columna enviada contra las montoneras del litoral (con su jefe a la cabeza) se sublevó. Desde allí las tropas sublevadas intimaron al Director que abandone el mando, en un claro apoyo al caudillo oriental. Frente a tal situación, y sin la colaboración de sus propios aliados, Alvear presentó su renuncia ante la Asamblea el 14 de abril de $1815 .{ }^{43}$

\section{Disolución de la Asamblea}

La caída de Alvear arrastró la suerte de la Asamblea, que es formalmente disuelta por el Cabildo de Buenos Aires el 15 de abril de 1815. El cabildo reasumió así de manera provisoria la autoridad soberana y pasó a dictar en consecuencia algunas disposiciones referidas a la creación de un gobierno provisional. Resolvió convocar al pueblo de Buenos Aires para que eligiese un grupo de electores con facultades para nombrar un gobierno provisorio hasta la reunión de un Congreso General de las Provincias. Así, una vez efectuado el escrutinio, se nombró al general Rondeau como Director Supremo Provisorio, quien por encontrarse al frente del ejército del norte, sería reemplazado por Álvarez Thomas en calidad de suplente.

Al mismo tiempo, el cabildo dispuso la creación de un organismo colegiado de carácter moderador: la "Junta de

\footnotetext{
43 Ampliar en PALACIO, Ernesto, Historia Argentina 1515-1955, A. Peña Lillo Editor S.A., Bs. As. 1979, pag. 216.

44 Los electos resultaron ser: Esteban Gascón, Pedro Medrano, Antonio Sáenz, Mariano Serrano y Manuel de Anchorena. Como suplentes fueron designados: Manuel Obligado y Domingo
} 
Observación" compuesta por cinco ciudadanos "virtuosos" que daría al nuevo gobierno un Estatuto provisional. ${ }^{44}$

A la hora de analizar los sucesos que rodearon la crisis de la Asamblea del año XIII, en tanto que no logró sus objetivos de independencia y constitución, debemos tener presente la situación europea de aquellos años. Europa había cambiado radicalmente en los primeros meses de 1814. Con la abdicación de Napoleón y la vuelta al trono de España de Fernando VII desapareció la causa que justificaba la revolución americana. Los pueblos de las colonias se habían levantado en nombre del rey cautivo, de allí que su liberación y regreso al poder no les daba más alternativas que recibirlo con beneplácito y deponer las armas. Pero la partida estaba demasiado avanzada para retroceder.

El regreso del rey Fernando VII al trono de España trastocó los planes del grupo dirigente. Corrían fuertes versiones de que se estaba preparando en Cádiz una expedición contra los revolucionarios del Río de La Plata compuesta por más de 15.000 hombres. ${ }^{45}$ Todo esto, llevó a la Asamblea al desconcierto y a la improvisación, para terminar disolviéndose a poco mas de dos años de su creación sin poder cumplir su cometido inicial.

El Estatuto Provisional de 1815 dado por la Junta de Observación estableció que el Poder Ejecutivo debía convocar a las ciudades y villas de las provincias interiores a que envíen diputados a un Congreso a reunirse en la ciudad de Tucumán. Dicho Congreso logró cumplir los dos objetivos que no pudo la Asamblea de Año XIII: Declaró la independencia en 1816 y sancionó una Constitución en 1819. ${ }^{46}$

\footnotetext{
Zapiola. Ver en IBAÑEZ, José. Historia de las Instituciones Políticas y Sociales en América y en el actual territorio argentino. Editorial Troquel SA, Bs. As. Sexta edición, 1962. Pag. 78

45 Ver LOPEZ ROSAS, José Rafael, Historia constitucional argentina, Editorial Astrea, Bs. As, 1984, 3ra. Edición, pag. 196.

46 La constitución de 1819 fue sancionada por el Congreso una vez que éste se había trasladado a Buenos Aires.
} 